\title{
PARENTS' PERCEPTIONS ON PREVIOUS AND CURRENT SCIENCE EDUCATION SYSTEM IN JAPAN
}

\author{
Kseniya Fomichova* and Taku Misonou \\ Department of Life and Environmental Sciences, University of Yamanashi \\ 4-4-37, Takeda, Kofu, Yamanashi, 400-8510 Japan. \\ *Corresponding e-mail: kseniya@yamanashi.ac.jp
}

\begin{abstract}
Parents'views, beliefs, and experiences greatly affect children's attitudes toward education. The research aimed to identify the parents' perception in the past, present, and their desired priorities in science education as well as investigated the adolescents' perceptions based on gender and academic performance on science. As a survey study, this research relied on a questionnaire as the primary method of data collection which the data gained then was analysed by using statistical descriptive (percentage). The results showed that the priorities in education have shifted toward physics and chemistry in recent decades. Moreover, biology and earth science were found to be perceived as 'easy' and 'secondary' areas in comparison to the 'superior' ones (physics and chemistry). This has been strengthened by the critical situation for earth science, as the education system of Japan often does not al low the students to select it. Thus, the parents wished for a more balanced system. There was a difference in adolescents' perceptions of science areas based on gender and academic performance. Physics and chemistry were associated with boys and top performers, while biology and earth science were supposed to 'fit' girls and low performers.
\end{abstract}

Keywords: Adolescents' perceptions, parents' perceptions, science education

(C) 2018 Department of Biology Education, FTTE, University of Muhammadiyah Malang, Indonesia

\section{INTRODUCTION}

There are three main groups of stakeholders in school teaching and learning: students, their parents and teachers. Parents' societal beliefs, experiences and views of children's future, greatly affect children's perception of school education, and in particular, science (Chang, Yeung, \& Cheng, 2009; Halim, Abd Rahman, Zamri, \& Mohtar, 2017; Mullis, Martin, Foy, \& Arora, 2011; Oscarsson, Jidesjö, Strömdahl, \& Karlsson, 2012; Sjøberg \& Schreiner, 2010).

Adolescents' attitudes toward science education have been studied extensively since the late 1960s. There is an extensive body of knowledge on students' perception of science, careers, and economic issues in education. Many study outlines such as gender and cultural result in attitudes toward science (Meyers-Levy \& Loken, 2015; Sjøberg \& Schreiner, 2010), economic factors in learning (Sjøberg \& Schreiner, 2010), change of perception (Mullis et al., 2011), and the representation in science and technology careers (Ecklund, Lincoln, \&
Tansey, 2012; Mann \& DiPrete, 2013; MossRacusin, Dovidio, Brescoll, Graham, \& Handelsman, 2012).

In a major review of the research conducted during last four decades from the 20th century, Osborne, Simon, and Collins (2003) found that there was an overall decrease in student attitudes toward science education. Various studies from this period also highlighted a general ignorance of science in society (Durant, Evans, \& Thomas, 1989; Miller, 2004; Sturgis \& Allum, 2004). All of this has happened during a time of an increasing realization of the economic, technological and cultural importance of scientific knowledge in society (Mullis et al., 2011; Osborne et al., 2003). In response to this, many countries have made significant investments starting initiatives to increase interest in science and science education, such as the American Committee on STEM Education (CoSTEM), the Committee for Public Understanding of Science (COPUS) in UK, the European Science Education Research Association (ESERA), and the 
International Organization for science and Technology Education (IOESTE) and so on. One of the recent initiatives in science education was the 'Decade of Education for Sustainable Development' (Wals, 2014). However, its goals were seen as having been largely unmet (Ontong \& le Grange, 2015). To accomplish them, a scientifically and environmentally literate population is necessary (Wals, 2014).

Schools of science education in many countries are often a race in order to pass exams to the next school year and ultimately universities (Paton, 2012; Zheng \& Qu, 2015). Therefore, the instruction may be focused on the topics that are required for such exams, especially in later years. As the result, some science topics, often in biology and environmental science, are shortened or omitted. The extent of this issue is significant in Japan (Fomichova \& Misonou, 2015). This deficit in training definitely affects the attitudes of students towards these fields of science.

In other countries the government artificially creates the demand for scientists in a particular field without solid economic and social reasons. As the result, this field becomes popular for a period of time, during which specialists are 'overproduced'. In several years, their employment rate becomes low, and graduates are forced to accept a low salary, change the profession, or emigrate. These are just several examples of how science education becomes unbalanced as the result of politics and economic issues (Boyer, Wolf Hamil, \& Professor, 2008; Chimombo, 2005; Sukasni \& Efendy, 2017). However, it should be balanced in order to nurture an overall scientific literacy, a desire to study various fields of science and possibly become a scientist.

This research was mainly focused on parents of children attending lower and upper secondary schools in Japan. It explored parents' beliefs, experiences, and views in science education. The goal was to investigate, what the differences among the areas of science schools (physics, chemistry, biology, earth science and environmental science) exist in parents' perception. In particular, if parents consider any areas of science, and biology in particular, to be a 'secondary' area of science, i.e. less 'prioritized' or less 'important', and what perception of this science area they have in relation to children's gender and academic performance. Notwithstanding that there were some previous researches in education have investigated many issues, however these areas have not been sufficiently studied. Therefore, it is extremely important to address them, as they may have a profound impact on the perception of science in society, and the success of science and environmental education.

This study used mixed methods to address the following objectives: (1) to investigate the differences among the areas of science based on parents' experiences in science education, i.e. in factual educational background, interests, selfassessment of knowledge in science; (2) to study parents' assessment of past and present priorities in school of science education in term of what areas of science, in their opinion, were emphasized in the past (when respondents were students) and are emphasized now. Besides, what areas of science are evaluated by parents as 'important' in general and depending on children's careers in future; (3) to study parents' perception of science areas in relation to children's gender and academic performance, i.e. what areas of science are evaluated as corresponding boys, girls, and adolescents with different academic performance ('good and bad marks' in science).

\section{METHOD}

The methods used for the first to third objectives included an analysis of primary data obtained by conducting surveys and was using questionnaires for parents of the children who were attending lower and upper secondary schools in Japan. The secondary data were obtained by reviewing research reports and other documents.

The questionnaire for parents was consisted of 16 questions as follows. (1) Gender of respondents. (2) Age. (3-4) Children, their ages. (5) Educational background: a) a university degree in natural or social sciences; b) a completion of a college or a vocational school in natural or social sciences; c) a completion of upper secondary school; d) others. (6) Lack of knowledge in areas of science (selfassessment). (7) Level of interest towards areas of science while attending: a) lower secondary schools, b) upper secondary schools. (8) Subjects chosen by respondents when they were attending upper secondary schools. (9) Subjects that respondents wished to choose when they were attending upper secondary schools. (10) Priority areas of science when respondents were 
attending lower and upper secondary schools. (11) Priority areas of science in the present school. (12) Areas of science that respondents would prefer to be prioritized in children's education. (13) Attitudes of children towards areas of science depending on gender. (14) Attitudes of children towards areas of science depending on academic performance. (15) Areas of science 'important' for children in regard to entrance exams and studying in universities. (16) Areas of science 'important' for children's future if they choose medicine or school science teaching as careers.

The survey was conducted during two events related to education held in Yamanashi prefecture, Japan. The visitors attending these events and accompanying children of the required age (lower and upper secondary school students) were selected randomly and asked for participation. They were informed that the results would be used for publications in the area of educational research and further studies. The respondents were allowed to choose more than one answer in some certain questions. In total, 100 answers were selected and analysed by using statistical descriptive (percentage). This sample size was considered as sufficient for the purposes of the present study.

\section{RESULTS AND DISCUSSION}

The respondents consisted of 78 females and 22 males in which the age range was from 35 to 50 years old. In addition, 40 of them graduated from university (22 attended for natural science, 16 for social science, and six for others), 36 from technical school (four for natural science, 28 for social science, and four for others), and four from others.

\section{Respondents' background}

The parents were asked to identify science subjects (Physics $(\mathrm{Ph})$, Chemistry $(\mathrm{Ch})$, Biology (Bi), and Earth Science (ES)) that they chose while they were studying in upper secondary schools (grades 10 to 12). This aimed to get the better understanding of parents' background in science education. The results are presented in Table 1.

Table 1. The science subjects chosen by respondents in upper secondary schools (multiple selection)

\begin{tabular}{ccccc}
\hline Subject & Ph & Ch & Bi & ES \\
\hline Parents (\%) & 29.79 & 64.17 & 73.33 & 16.04 \\
\hline Answers (n=96) & & &
\end{tabular}

According to Table 1, most of the respondents $(73 \%)$ chose biology when they were studying in upper secondary schools; meanwhile $64 \%$ of them chose chemistry. While about $30 \%$ respondents' option was physics, and the earth science was the lowest voters $(16 \%)$.

The difference occurred may be affected by gender perspective (Alon \& Diprete, 2015; Kumari \& Saraladevi, 2012). As the number of women electors was higher than the men, i.e. 78 female and 22 male, the subject which tended to be chosen by women would also higher. This in line with some previous studies which concluded that there was a segregation trend in choosing science major (Mann \& DiPrete, 2013), particularly in physics and biology (Ecklund et al., 2012). Thus, Moss-Racusin et al. (2012) suggested interventions on gender bias to increase women participation in science.

In contrast to physics, chemistry, and biology, earth science has been selected by a minority of students in upper secondary Japan schools. Many of them have been unable to select it even if they are prefer to do so. This due to the reason that earth science is often associated with environmental studies.

As the school education system designates selection options among science subjects in upper secondary schools, adolescents face a complex choice for some argumentations. First, many of them do not have 'favourite' areas of science which lead them not to choose any. Second, a substantial ratio of students do not know what the specialty they would like to study in the future, so that they lack of information of what areas of science would be useful for them. The limited selection options of adolescent favourite areas was also the considerable reason which unabled them to choose the subjects at the same time. Finally, the students' science attitudes, in some way, are significantly influenced by type schools (Dilek Eren, Karadeniz Bayrak, \& Benzer, 2015) and country (Yamamoto, Holloway, \& Suzuki, 2016). Thus, specific rules issued by countries, universities, and particular faculties often put students in a position when they have to study in 'uninteresting' areas of science to pass entrance exams. For example, in Japan many medical universities require physics to pass the entrance exams, while biology is not required. Finally, there is a possibility that adolescents' choice of disciplines is approved by their 
parents (Halim et al., 2017), teachers, or other people, and they have to rethink it.

Therefore, in this study, the parents were asked about what areas of science they chose while they were studying in upper secondary schools. The results are presented in Table 2.

Table 2. Science subjects which respondents willed to choose in upper secondary schools (multiple selection)

\begin{tabular}{ccccc}
\hline Subject & Ph & Ch & Bi & ES \\
\hline Parents (\%) & 24.95 & 45.36 & 45.36 & 29.48 \\
\hline \multicolumn{2}{l}{ Answers (n=97) }
\end{tabular}

According to Table 2, the equal percentage of respondents' preference (45\%) was to study about chemistry and biology. While the two other subjects, the earth science and physics, were only chosen by $30 \%$ and $25 \%$ respondents respectively. A comparison of Tables 1 and Table 2 shows that there were more respondents who took physics, chemistry, and biology than those who willed to do so. While $70 \%$ respondents learnt biology, only $44 \%$ willed to learn it. A similar situation occurred in chemistry (the reality was $62 \%$, the expectation was $44 \%$ ) and physics (the reality was $29 \%$, the expectation was only 25\%). Interestingly, the different situation taken place for earth science in which $15 \%$ respondents took the subject even though there was about $29 \%$ wished to take it.

The answers of the targeted population, summarized in Table 2, were more 'even' in trend between areas of science than their factual choices described in Table 1. It is especially interesting if to consider that almost $80 \%$ of the respondents were females. These results mean that respondents were 'forced' to learn science while they preferred not to. The OECD reported that Japan has high standard for entrance exam in which Japanese dislike to conduct (OECD, 2010). The findings drove to assume that biology and chemistry were chosen not because of the more positive attitude towards them, but as comparatively 'better' (possibly, 'easier') options in comparison to physics. Consequently, respondents expressed the less positive attitude towards physics.

A special position of earth science in the system of school education in Japan was highlighted by the both Table 1 and Table 2 . The number of respondents who wanted to select physics, chemistry, and biology were smaller in comparison to those who actually chose them while being students of upper secondary schools. Only in earth science the more respondents wished to select than actually did so. Obviously, in some schools in Japan, there was no possibility to select this area. It also could be rather 'useless' for adolescents in term of the contribution in university and college entrance exam. There are various factors drive students' curiosity toward science i.e. teaching method (Husamah, Fatmawati, \& Setyawan, 2018), science curriculum, parent, and social life (Akpınar, Yıldız, Tatar, \& Ergin, 2009), school type (Dilek Eren et al., 2015), and the belief of science difficulty (The Malta Council for Science \& Technology, 2015).

This study also outlines the two following issues. The first is a general 'unwillingness' to study science. The second is that biology could have been chosen not because the respondents had a positive attitude toward it, but because they could have a more negative perception of the other areas of science compare to biology, in particular, of physics and chemistry. While the parents were not required to explain their choice of science disciplines, biology could have been chosen as an 'easier' option compare to the two other subjects.

\section{Self-assessment of knowledge in science}

Self-assessment of knowledge and abilities in science is the major factor determines a person's attitude towards it. That is why respondents were asked to answer the following question: 'Evaluate own lack of knowledge in science by the following scale: 1 ) do not feel at all; 2) almost do not feel; 3) feel sometimes; 4) feel often; 5) feel all the time'. The areas of science were physics $(\mathrm{Ph})$, chemistry $(\mathrm{Ch})$, biology (Bi), earth (ES), environmental (EnS), agricultural science (AS) and medical (MS) sciences. The mean of respondents' replies is presented in Table 3.

Table 3. Parents' self-assessment of their knowledge in science

\begin{tabular}{ccccccc}
\hline \multicolumn{6}{c}{ Parents' knowledge in science areas (mean) } \\
\hline Ph & Ch & Bi & ES & EnS & AS & MS \\
\hline 3.12 & 3.35 & 2.90 & 3.20 & 3.12 & 3.37 & 3.25 \\
\hline \multicolumn{7}{c}{ Answers $(\mathrm{n}=100)$} \\
\end{tabular}

According to Table 3, in all areas of science, the respondents felt a deficiency of knowledge 'sometimes'. However, in chemistry and agricultural sciences is slightly higher than in other areas. These two areas were followed by medicine (3.25), earth science (3.20), physics 
and environmental science (3.12), and the last was biology (2.90).

It can be seen that the respondents have experienced the lack of knowledge in agricultural sciences more than in medical. In addition, the level biology knowledge was evaluated as the most sufficient among all areas, while agricultural science has been considered to be the least sufficient. It indicated that biology is considered to be the easiest area compare to the others. The level of knowledge, somehow, contributes to someone's science preferences (Alrehaly, 2011). There was a substantial difference in respondents' perception of biology, agricultural science, and environmental science, i.e. they were possibly considered to be independent (rather unrelated) categories.

\section{Attitudes towards areas of science while being at school}

The most fundamental concept of perception of science is the level of interest towards it. Respondents were asked to evaluate own interest towards areas of science as they were students of lower and upper secondary schools. The assessment scale was: 1 (dislike); 2 (indifferent); 3 (little interest); 4 (moderate interest); 5 (deep interest). The mean of responses is presented in Table 4.

Table 4. Parents' attitudes towards science areas while being at school

\begin{tabular}{ccccc}
\hline School/Subject & Ph & Ch & Bi & ES \\
\hline Lower secondary & 2.38 & 2.96 & 3.32 & 2.76 \\
Upper secondary & 2.18 & 2.82 & 3.32 & 2.78 \\
\hline
\end{tabular}

Answers ( $\mathrm{n}=100)$

Respondents' perception of science areas in the both lower (grades 7-9) and upper (grades 10-12) secondary schools was similar. As respondents were attending lower and upper secondary schools, their attitude towards science ranges from 'indifference' in physics to between 'little' and 'moderate' interested in biology. Some countries witnessed the same condition in various age levels such as Africa (Reddy, 2017), Indonesia (Yamtinah, Masykuri, \& Syahidul Shidiq, 2017) Malta (The Malta Council for Science \& Technology, 2015), and Turkey (Pehlivan et al., 2011).

Notwithstanding that there was no difference of the attitudes based on education levels, but it can be seen that there were preference levels showed. The highest level of interest was expressed to biology, even though it did not reach 'moderate' one. A slightly less positive attitude wass expressed towards chemistry and earth science. The lowest level of interest was observed in physics. This perception was possibly influenced by respondents' gender.

\section{Assessment of priorities in school science education}

The respondents were asked to indicate the prioritized science areas as they were school students, and in the present time. The questions were designated in multiple selection form. The respondents could either select one area of science, several ones, or the option 'all equally'. The summary of parents' answers concerning the time when they were students is presented in Table 5.

Table 5. Priority areas of science as the respondents attended school (multiple selection)

\begin{tabular}{lccccc}
\hline \multicolumn{1}{c}{ School/Subject } & Ph & Ch & Bi & ES & All \\
\hline Lower secondary* $^{*}$ & 31 & 40 & 34 & 4 & 40 \\
Upper secondary** $^{*}$ & 33 & 44 & 36 & 6 & 34 \\
\hline * Answers (n=98) & & & & & \\
** Answers (n=96) & & & & &
\end{tabular}

According to Table 5, it is clear that the respondents' priority in science areas was similar between the two school stages. There were more respondents who prioritized the science areas compare those who stated that the all areas were equal. As many as 40 respondents of lower secondary schools stated that the all science areas were equal, while 58 of them thought that the areas were different. The 40 respondents prioritized chemistry, while the other 34 and 31 selected biology and physics respectively. Therefore, chemistry was considered to be slightly more emphasized than the two others. The same tendency was observed in the upper secondary schools. In contrast, there only four and six respondents considered the earth science as their priority.

Table 6 shows he priority areas of science in the present school. It can be seen that 42 out of 94 and 36 out of 92 respondents considered that the all science areas were equally emphasized in present lower and upper secondary schools (respectively). Moreover, physics and chemistry were more prioritized over biology and earth science. No respondent selected earth science as their priority in regard to the lower secondary schools, and only three of them selected it in regard to the upper secondary schools. 
Table 6. Prioritized areas of science in present school (multiple selection)

\begin{tabular}{lccccc}
\hline \multicolumn{1}{c}{$\begin{array}{c}\text { School/ } \\
\text { Subject }\end{array}$} & Ph & Ch & Bi & ES & All \\
\hline Lower secondary* & 31 & 34 & 26 & 0 & 42 \\
Upper secondary** & 36 & 36 & 23 & 3 & 36 \\
\hline *Answers (n=94) & & & & & \\
** Answers (n=92) & & & & &
\end{tabular}

The comparison of Table 5 and Table 6 shows that in respondents' opinion, the priorities in schools have shifted since they have been students. In particular, chemistry became less emphasized than before, and biology became less emphasized than physics and chemistry. However, the situations of earth science remained unchanged.

The respondents were asked, what science areas they wished to prioritize in their children's education. Parents could choose one area of science, several areas, or 'all equally'. The results are presented in Table 7.

Table 7. Science areas that respondents wish to be prioritized in children's education

\begin{tabular}{lccccc}
\hline \multicolumn{1}{c}{ School/Subject } & Ph & Ch & Bi & ES & All \\
\hline Lower secondary* $^{*}$ & 10 & 26 & 22 & 14 & 60 \\
Upper secondary $^{*}$ & 14 & 26 & 26 & 16 & 58 \\
\hline Answers $(\mathrm{n}=100)$ & & & & &
\end{tabular}

According to Table 7, 60 and 58 out of 100 respondents would like all areas of science to be prioritized equally in children's education. Among the respondents who preferred the science areas to be emphasized differently, the number who selected chemistry and biology was higher than those who prioritized physics and Earth science.

The comparison of Table 6 and Table 7 shows that parents would like to have a more 'balanced' system of school science education than the present conditions. It can be seen that approximately $40 \%$ and $60 \%$ of respondents expressed their opinion that the all science areas should be equal whether it is in the past or in present schools. The other respondents have certain preferences in children's science education, but they obviously would like the earth science to be more prioritized than it is in the present school.

\section{Assessment of adolescent preferences in science depend on gender}

In gaining the data about parents' perception of adolescent attitudes towards science based on gender, participants were asked what areas of science boys and girls 'like'. The results are presented in Table 8.

Table 8. Parents' assessment of adolescent preferences in science based on gender (multiple selection)

\begin{tabular}{ccccc}
\hline \multirow{2}{*}{ Gender } & \multicolumn{4}{c}{ Parents (\%) } \\
\cline { 2 - 5 } & Ph & Ch & Bi & ES \\
\hline Boys & 62 & 70 & 12 & 16 \\
Girls & 6 & 22 & 86 & 12 \\
\hline
\end{tabular}

Answers $(n=100)$.

According to Table 8, the majority of respondents $(70 \%)$ presumed that chemistry is the most favorable area of science for boys, while the most preferable subjects for girls was biology (86\%). In parents' opinion, physics was the second most popular among boys (62\%) which then followed by earth science $(16 \%)$ and biology $(12 \%)$. This is different with the girls' choice. Chemistry, as the second sequence of the subject chosen by girls, the gap exist between chemistry (22\%) and biology was dramatic (64\%). Only $12 \%$ respondents suggested that girls 'like' earth science, and only $6 \%$ respondents chose physics. Therefore, there is a clear difference between girls and boys preference of science areas based on parents' point of view. Boys were expected to prefer chemistry and physics, while the girls were supposed to prefer biology. This in line with Reddy (2017) who found that boys were more interested in physic and chemistry, while girls were more inclined for biology.

Parents' assessment of adolescent preferences in science depend on performance as well as their involvement in their children's education (Topor, Keane, Shelton, \& Calkins, 2010). This has also been proven to improve the students' achievement (Karıbayeva \& Boğar, 2014; Wilder, 2014). The data about parents' perception of adolescent attitudes towards science based on academic performance were gained by asking the participants of what areas of science top and low performers 'like'. The results are presented in Table 9.

Table 9 shows that, according to respondents, top performers prefer physics and chemistry over biology and earth science, and the difference between these two blocks is obvious. As high as $88 \%$ and $66 \%$ of respondents assumed that students with a 'good' marks like physics and chemistry, while biology and earth science were the two last choices i.e. $14 \%$ and $8 \%$ respectively. In term 
of low performer preference subjects, the highest percentage was biology $(83 \%)$ which followed by earth sience (33\%), physics and chemistry as low as $10 \%$ and $7 \%$ in sequence.

Table 9. Parents' assessment of adolescent preferences in science based on performance (multiple selection)

\begin{tabular}{ccccc}
\hline \multirow{2}{*}{ Adolescents } & \multicolumn{4}{c}{ Parents } \\
\cline { 2 - 5 } & Ph & Ch & Bi & ES \\
\hline Top performers & 88 & 66 & 14 & 8 \\
Low performers & 10 & 7 & 83 & 33 \\
\hline
\end{tabular}

Answers $(n=100)$.

By comparing the data served in Table 8 and Table 9, it is clear that there were two blocks i.e. 1) physics and chemistry; and 2) biology and earth science. This clear pattern was strongly assumed related to the impact of children's gender on their academic performance in term of certain science areas. Possibly, one of the reasons is that biology and earth science were evaluated as 'simple' in comparison to physics and chemistry.

\section{Importance of science fields for children's academic career (parents' assessment)}

It is important to investigate, what areas of science, in parents' opinion, are the 'priority' ones. This due to their considerable impact on children's education in term of decisions, financial, as well as expectations (Mahamood et al., 2012). In this survey, the parents were asked to identify the areas that are 'important for children's future' if they continue studying in natural sciences or social sciences. The results are presented in Table 10.

Table 10. Parents' assessment of the importance of science areas for children's academic career

\begin{tabular}{cccccccc}
\hline \multicolumn{3}{c}{$\begin{array}{c}\text { Natural sciences } \\
\text { (parents, \%) }\end{array}$} & \multicolumn{4}{c}{$\begin{array}{c}\text { Social sciences } \\
\text { (teachers, \%) }\end{array}$} \\
\hline Ph & Ch & Bi & ES & Ph & Ch & Bi & ES \\
\hline $\mathbf{8 0}$ & 68 & 28 & 28 & 13 & 13 & 75 & 52 \\
\hline \multicolumn{3}{c}{ Answers $(\mathrm{n}=100)}$. & & & &
\end{tabular}

According to Table 10, 80\% and $68 \%$ of respondents suggested that physics and chemistry (respectively) to be 'important' for natural science students' future. While biology and earth science were considered as the less important area for them (28\% for each). In case the students choose social sciences, biology was selected as the most 'important' discipline by
$75 \%$ respondents, followed by earth science $(52 \%)$, physics $(13 \%)$ and chemistry $(13 \%)$.

It was also asked to the parents about the science areas which are 'important for adolescents' future' if they select careers in medical, as this is one of top choices, and teaching science. Parents were asked to conduct an assessment by the scale from 1 (the most important) to 4 (the least important). The results are presented in Table 11.

Table 11. Parents' assessment of the importance of science areas for children's careers in medical

\begin{tabular}{ccccc}
\hline \multirow{2}{*}{ Scale } & \multicolumn{4}{c}{ Parents (\%) } \\
\cline { 2 - 5 } & Ph & Ch & Bi & ES \\
\hline 1 & 18 & 29 & 48 & 0 \\
2 & 7 & 57 & 24 & 7 \\
3 & 64 & 9 & 18 & 4 \\
4 & 7 & 0 & 4 & 84 \\
\hline
\end{tabular}

Answers $(\mathrm{n}=100)$.

According to Table 11, if adolescents choose their career in medical, parents consider biology to be the most important area; the next suggestion was chemistry; while physics was presumed to be number three, and earth science was the least important. However, in case the adolescents decide to become school science teachers, the importance of science areas were in as follow sequence: physics, chemistry, biology, and earth science (Table 12).

Table 12. Parents' assessment of the importance of science areas for children's careers in teaching science

\begin{tabular}{ccccc}
\hline \multirow{2}{*}{ Scale } & \multicolumn{4}{c}{ Parents (\%) } \\
\cline { 2 - 5 } & $\mathrm{Ph}$ & $\mathrm{Ch}$ & $\mathrm{Bi}$ & ES \\
\hline 1 & 41 & 29 & 18 & 7 \\
2 & 20 & 41 & 18 & 7 \\
3 & 16 & 14 & 41 & 16 \\
4 & 11 & 5 & 11 & 59 \\
\hline \multicolumn{4}{c}{ Answers $(\mathrm{n}=100)}$. &
\end{tabular}

Table 1 to Table 12 highlighted several issues which were not reported previously. Biology has been often chosen by students in upper secondary schools of Japan and other countries. However, instead of choosing it due to the students' interest, the survey results proved that it was because biology is one of the requirements of entrance exams. Among Japanese family, the perception about the important of future career determines the student's attitudes toward science (Entrich, 2015). Moreover, it is believed that physics and 
chemistry are the more 'complex' disciplines than biology. Therefore, this subject has become the primary and 'forced' choice which may have a negative influence on students' attitudes towards learning in science.

Another negative aspect of this situation is that biology is perceived as an 'easy' area in comparison to physics and chemistry. As the result, it is considered as the 'superior' area. The earth science has a special status in comparison to other science areas. First, respondents may be unable to choose it while attending upper secondary schools. Therefore, while it may be recognized as an 'interesting' area, but it is often cannot be fulfilled because of the characteristics of school education in Japan. Second, this subject was considered as the 'secondary' and 'easy' science area.

The priorities in school of science education have shifted towards physics and chemistry since they graduated from upper secondary schools. However, this survey did not enquire about a particular period of time when, in respondents' opinion, this shift could have happened. Therefore, it is unclear, whether this assessment was based on certain changes of school education in Japan, or not. However, the respondents expressed a positive view of a more 'balanced' science education for their children.

There is a clear difference in perception of science areas depend on adolescents' gender and academic performance. Physics and chemistry were associated with boys and top performing students, while biology and earth science were supposed to 'fit' girls and low performers.

\section{CONCLUSION}

This study was focused on the societal perception of science, particularly in biology, in Japan. The results showed that the students' choice of science subjects in high schools of Japan was often a 'forced' one, and is caused by the requirements of entrance exams, parents' influence, and other factors. It is also found that biology and earth science were perceived as 'easy' and 'secondary' areas in comparison to 'superior' physics and chemistry. The critical situation occurred in earth science as the Japan education system often does not allow students to select it. Such situation may results major negative outcomes for science and environmental education. The priorities in education have shifted towards physics and chemistry in recent decades. However, they wish for a more balanced system.

\section{REFERENCES}

Akpınar, E., Yıldız, E., Tatar, N., \& Ergin, Ö. (2009). Students' attitudes toward science and technology: An investigation of gender, grade level, and academic achievement. Procedia Social and Behavioral Sciences, 1, 2804-2808. http:// doi.org/10.1016/j.sbspro.2009.01.498

Alon, S., \& Diprete, T. A. (2015). Gender Differences in the Formation of a Field of Study Choice Set. http://doi.org/10.15195/ v2.a5

Alrehaly, E. D. (2011). Parental attitudes and the effects of ethnicity: How they influence children's attitudes toward science education. Retrieved from https://files. eric.ed.gov/fulltext/ED515978.pdf

Boyer, A., Wolf Hamil, B., \& Professor, A. (2008). Problems Facing American Education. Focus on Colleges, Universities, and Schools, 2(1), 1-9. Retrieved from http://www.national forum.com/ElectronicJournalVolumes/Bo yer, Ashley Problems Facing American Education.pdf

Chang, S.-N., Yeung, Y.-Y., \& Cheng, M. H. (2009). Ninth Graders' Learning Interests, Life Experiences and Attitudes Towards Science \&amp; Technology. Journal of Science Education and Technology, 18(5), 447-457. http://doi.org/10.1007/s10956009-9162-6

Chimombo, J. P. G. (2005). Issues in basic education in developing countries: An exploration of policy options for improved delivery. Journal of International Cooperation in Education, 8(1), 129-152. Retrieved from https://home.hiroshimau.ac.jp/cice/wp-content/uploads/2014/03/8 -1-11.pdf

Dilek Eren, C., Karadeniz Bayrak, B., \& Benzer, E. (2015). The examination of primary school students' attitudes toward science course and experiments in terms of some variables. Procedia-Social and Behavioral Sciences, 174, 1006-1014. http://doi.org/10.1016/j.sbspro.2015.01.12 45

Durant, J. R., Evans, G. A., \& Thomas, G. P. (1989). The public understanding of 
science. Nature, 340(6228), 11-14. http://doi.org/10.1038/340011a0

Ecklund, E. H., Lincoln, A. E., \& Tansey, C. (2012). Gender segregation in elite academic science. Gender \& Society, 26(5), 693-717. http://doi.org/10.1177/08 91243212451904

Entrich, S. R. (2015). The decision for shadow education in Japan: Students' choice or parents' pressure? Social Science Japan Journal, 18(2), 193-216. http://doi.org/ 10.1093/ssij/jyv012

Fomichova, K., \& Misonou, T. (2015). Teachers assessment of Japanese lower secondary school biology education teachers' assessment of biology education in comparison to other areas of science in lower secondary schools of Japan-A case study. Asian Journal of Biology Education, 8. Retrieved from http://www.aabe.sakura.ne.jp/Journal/Pap ers/Vol8/02 Fomichova.pdf

Halim, L., Abd Rahman, N., Zamri, R., \& Mohtar, L. (2017). The roles of parents in cultivating children's interest towards science learning and careers. Kasetsart Journal of Social Sciences, 39(2), 190 196. http://doi.org/10.1016/J.KJSS.2017. 05.001

Husamah, H., Fatmawati, D., \& Setyawan, D. (2018). OIDDE learning model: Improving higher order thinking skills of biology teacher candidates. International Journal of Instruction, 11(2), 249-264. http://doi.org/10.12973/iji.2018.11217a

Karıbayeva, A., \& Boğar, Y. (2014). To what extent does parents' involvement in middle school influence children's educational progress? (pp. 529-533). Elsevier Ltd. http://doi.org/10.1016/ j.sbspro.2014.09.222

Kumari, S. N., \& Saraladevi, K. (2012). Gender differences in attitude towards science teaching and learning styles among adolescents. International Journal of Science and Research (IJSR) ISSN, 3. Retrieved from www.ijsr.net

Mahamood, S. F., Tapsir, R., Saat, A., Ahmad, S., Wahab, K. A., Awang Boon, H., ... Rahman, A. (2012). Parental attitude and involvement in children's education: A study on the parental aspiration among form four students in Selangor-review under responsibility of Centre for Environment-Behaviour Studies (cE-Bs),
Faculty of Architecture, Planning \&amp; Sur. In Procedia-Social and Behavioral Sciences (Vol. 42, pp. 117-130). http:// doi.org/10.1016/j.sbspro.2012.04.173

Mann, A., \& DiPrete, T. A. (2013). Trends in gender segregation in the choice of science and engineering majors. Social Science Research, 42(6), 1519-1541. http://doi.org/10.1016/J.SSRESEARCH.2 013.07.002

Meyers-Levy, J., \& Loken, B. (2015). Revisiting gender differences: What we know and what lies ahead. Journal of Consumer Psychology, 25(1), 129-149. http://doi.org/10.1016/J.JCPS.2014.06.003

Miller, J. D. (2004). Public understanding of, and attitudes toward, scientific research: What we know and what we need to know. Public Understanding of Science, 13(3), 273-294. http://doi.org/10.1177/ 0963662504044908

Moss-Racusin, C. A., Dovidio, J. F., Brescoll, V. L., Graham, M. J., \& Handelsman, J. (2012). Science faculty's subtle gender biases favor male students. Proceedings of the National Academy of Sciences, 109(41), 16474-16479. http://doi.org/10. 1073/pnas.1211286109

Mullis, I. V. S., Martin, M. O., Foy, P., \& Arora, A. (2011). TIMSS 2011 International Results in Mathematics. Chestnut Hill, USA: TIMSS \& PIRLS of Education, Boston College and International Association for the Evaluation of Educational Achievement (IEA). Retrieved from https://timss andpirls.bc.edu/timss2011/downloads/T11 _IR_Mathematics_FullBook.pdf

OECD. (2010). Japan: A Story of Sustained Excellence. OECD. http://doi.org/10.1787 /888932366712

Ontong, K., \& le Grange, L. (2015). The reconceptualisation of sustainability after the decade of education for sustainable development. Tydskrif Vir Geesteswetenskappe, 55(1), 50-61. http://doi.org/10.17 159/2224-7912/2015/v55n1a4

Osborne, J., Simon, S., \& Collins, S. (2003). Attitudes towards science: a review of the literature and its implications. International Journal of Science Education INT. J. SCI. EDUC, 25(9), 1049-1079. http://doi.org/10.1080/09500 69032000032199

Oscarsson, M., Jidesjö, A., Strömdahl, H., \& 
Karlsson, K.-G. (2012). Science in society or science in school: Swedish secondary school science teachers' beliefs about science and science lessons in comparison with what their students want to learn. Nordic Studies in Science Education, 5(1), 18. http://doi.org/10.5617/nordina.280

Paton, G. (2012). Schools "shun traditional values in race for exam results"Telegraph. Retrieved July 17, 2018, from https://www.telegraph.co.uk/education/ed ucationnews/9268176/Schools-shun-tradi tional-values-in-race-for-exam-results.ht $\mathrm{ml}$

Pehlivan, H., Köseolu, P., Üniversitesi, H., Fakültesi, E., Bölümü, E. B., Doç, Y., ... Eitimi, B. (2011). The reflections of certain social factors concerning science high school students into their attitudes towards physics course. In Procedia Social and Behavioral Sciences (Vol. 15, pp. 605-608). http://doi.org/10.1016/j.sbs pro.2011.03.148

Reddy, L. (2017). Gender differences in attitudes to learning science in grade 7 . African Journal of Research in Mathematics, Science and Technology Education, 21(1), 26-36. http://doi.org/ 10.1080/18117295.2017.1279450

Sjøberg, S., \& Schreiner, C. (2010). The ROSE project An overview and key findings. Retrieved from https://roseproject.no/ network/countries/norway/eng/nor-Sjober g-Schreiner-overview-2010.pdf

Sturgis, P., \& Allum, N. (2004). Science in Society: Re-Evaluating the Deficit Model of Public Attitudes. Public Understanding of Science, 13(1), 55-74. http://doi.org/ $10.1177 / 0963662504042690$

Sukasni, A., \& Efendy, H. (2017). The problematic of Education system in Indonesia and reform agenda. International of Education, 9(3), 183-199. http://doi.org/10.5296/ije.v9i3.11705

The Malta Council for Science \& Technology.
(2015). Perception and Attitudes towards Science. Kalkara. Retrieved from http://esplora.org.mt/wp-content/uploads/ 2015/02/2014-MCST-Perception-and-Atti tudes-towards-Science.pdf

Topor, D. R., Keane, S. P., Shelton, T. L., \& Calkins, S. D. (2010). Parent involvement and student academic performance: A multiple mediational analysis. Journal of Prevention \& Intervention in the Community, 38(3), 183-197. http://doi. org/10.1080/10852352.2010.486297org/1 $0.1080 / 10852352.2010 .486297$

Wals, A. E. J. (2014). Sustainability in higher education in the context of the UN DESD: a review of learning and institutionalization processes. Journal of Cleaner Production, 62, 8-15. http://doi.org/10. 1016/J.JCLEPRO.2013.06.007

Wilder, S. (2014). Effects of parental involvement on academic achievement: a meta-synthesis. Educational Review, 66(3), 377-397. http://doi.org/10.1080/00 131911.org/10.1080/00131911

Yamamoto, Y., Holloway, S. D., \& Suzuki, S. (2016). Parental engagement in children's education: Motivating factors in Japan and the U.S. School Community Journal, 26(1). Retrieved from http://www.school communitynetwork.org/SCJ.aspx

Yamtinah, S., Masykuri, M., \& Syahidul Shidiq, A. (2017). Gender differences in student's attitudes toward science: an analysis of students' science process skill testlet instrument. In AIP Conference Proceedings (Vol. 4, pp. 030003-1030003-6). New York: American Institute of Physics. http://doi.org/10.1063/1.499 5086

Zheng, L. L., \& Qu, L. H. (2015). Application of microRNA gene resources in the improvement of agronomic traits in rice. Plant Biotechnology Journal, 13(3), 329336. http://doi.org/10.1111/pbi.12321 